\title{
Fiscalidad y población pechera en tierra de Behetrías: El servicio de Galeotes a fines del siglo XVII
}

\author{
Juan M. CARretero Zamora
}

El presente trabajo tiene como finalidad exclusiva presentar una fuente de indudable interés para el estudio de la fiscalidad y la demografía histórica castellanas en el siglo XVII. La fuente utilizada se encuentra en dos legajos que, bajo el título de "servicio de galeotes de las tierras de Behetrias", se hallan depositados en la sección de Contadurias Generales del archivo general de Simancas ${ }^{1}$; ambos legajos reproducen la misma documentación: los cuadernos de repartimiento del servicio de galeotes desde la época de Felipe II hasta la receptoria del servicio de 1702-1709. Además de la información fiscal, que abarca por septenios el período mencionado, los tres últimos repartimientos -fechados en 1688, 1695 y 1702 - contienen pormenorizados padrones de la población sujeta a contribución. No incluye, por tanto, el volumen total de población al ser padrones fiscales, aunque si menciona las villas y lugares exentos; esto es, aquéllos cuya población era hidalga, pero, desgraciadamente, sin evaluarla siquiera groseramente.

Como la mayoría de las fuentes fiscales del antiguo régimen (y más concretamente para el siglo XVII) la información demográfica contenida en los repartimientos presenta notables obstáculos para su valoración y análisis ${ }^{2}$. Asi, los repartimientos del servicio de galeotes vienen caracterizados por el laconismo en su contenido: mencionan la villa o lugar, la merindad a la que pertenece, cantidad en maravedies del servicio y número de vecinos pecheros; por ejemplo, de la villa de Torquemada, en la merindad de Cerrato, se decía:

AGS, Contadurias Generales, legajos 1.526 y 2.779 .

2 En este punto, el estudio de MARTin Galán, M., «Fuentes y métodos para el estudio de la demografía histórica castellana durante la Edad Moderna", en Hispania, 148 (1981). 


\section{MERINDADES DE LA TIERRA DE BEHETRIAS}

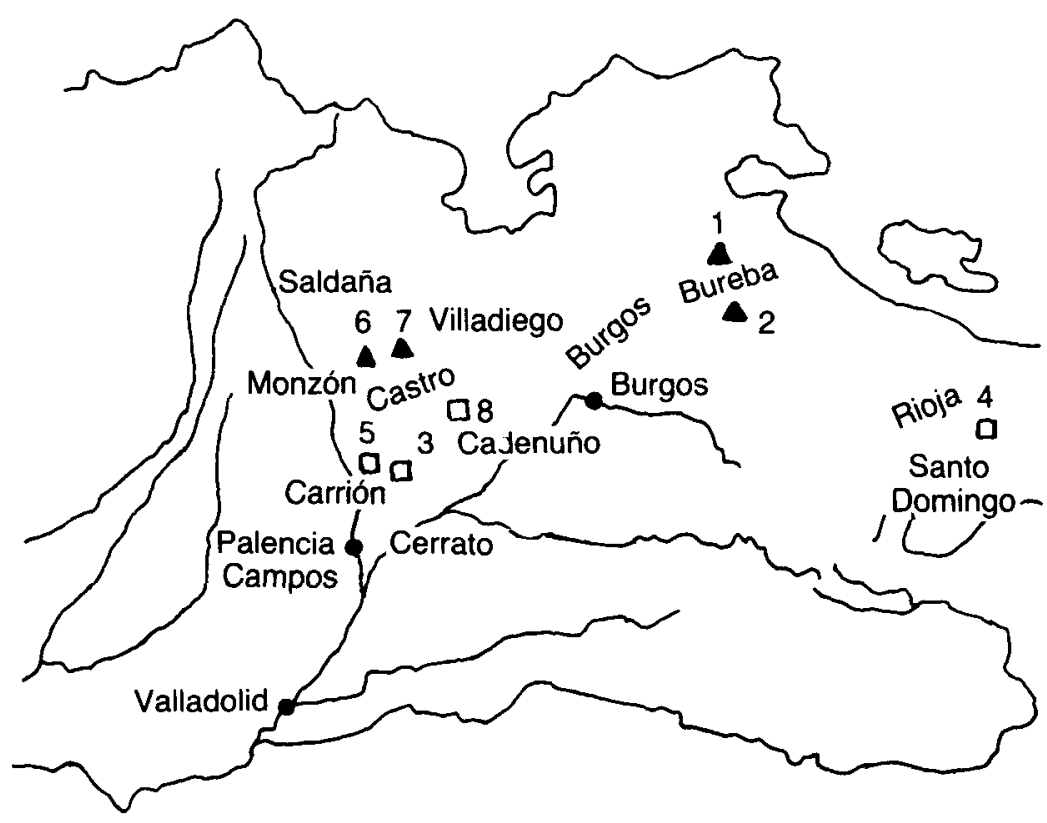

Villas y lugares despoblados

- Poblaciones con vecinos en su totalidad hidalgos

1 La Parte

2 Castil de Lences

3 Puente Itero

4 Manjarres

5 Perex

6 Tarragosa

7 Hormicedo

8 Ruyales del Páramo 
«A la villa de Torquemada le estavan repartidos por 132 vecinos, a razón cada uno de 1.490 maravedíes, 196.680 maravedies. Hecha la vaja de la grazia de Su Magestad de los dichos 300 maravedies por cada uno, quedan de paga líquida a la Real Hazienda que deve hazer dicha villa, 157.080 maravedies" ${ }^{3}$.

Es decir, no menciona si los vecinos incluyen a viudas y menores (aunque la existencia de cifras con decimales, contempla esa posibilidad) $y$, menos aún, el porcentaje incluso aproximado de la población privilegiada.

No obstante estas limitaciones, los repartimientos aportan otros datos muy útiles: los lugares despoblados y aquéllos - como he indicado-con población en su totalidad fiscalmente exenta por hidalguía general. Veamos algunos ejemplos: «A Manjarrés (merindad de Rioja) no se le reparte por estar despoblado" ${ }^{4}$, "A Santaolalla no se le reparte por ser todos hidalgos" ${ }^{5}$.

Sobre su contenido fiscal las limitaciones ya reseñadas vuelven a reproducirse, aunque con menor trascendencia para su análisis e interpretación. Se echa de menos, sin embargo, algunas informaciones preciosas como la existencia o no de cáñamas (que nos proporcionaría la estructura, aunque fuera muy vaga, de la riqueza en renta y propiedad de los pecheros), o bien, si pese a ser una carga fiscal personal y directa, en la práctica, se arbitraron mecanismos de pago habituales en otro de tipo de servicios (ordinario y extraordinario, millones, etc.) como eran la sisa sobre productos básicos (carns, aceite, vinagre, pescado, etc.), el arrendamiento de tierras concejiles, el recurso a los propios y arbitrios municipales, préstamos, censos, etc. En este punto, sólo el análisis de las fuentes municipales podrá definir los medios de pago reales.

\section{EL SERVICIO DE GALEOTES: ASPECTOS FISCALES}

De origen medieval, el servicio de galeotes constituyó una carga fiscal que soportaron los vecinos pecheros de las tierra denominadas de «behetría". El fundamento de tal prestación a la Corona nació de la antigua

${ }^{3}$ AGS, Contadurias Generales, leg. 2779, servicio de 1702.

4 Ibidem, servicio de 1695.

5 Ibídem, servicio de 1695, Merindad de Bureba. 
obligación de los pecheros de estas tierras de la Castilla del norte de servir con un determinado número de galeotes a las necesidades de la real armada. Sin embargo, desde la época de Juan II dicha prestación personal se transformó por permuta en una cantidad determinada de dinero ${ }^{6}$.

Hasta bien entrado el siglo XVI — según el parecer de Carande ${ }^{7}$ esta renta careció de continuidad y significación para la real hacienda. No obstante, en mi opinión y ante la documentación manejada, el servicio de galeotes se encontraba plenamente configurado en $1538^{8}$, puesto que en la carta receptoría del servicio de ese año Carlos I da a entender que el impuesto tenía cierta tradición anterior: «... que esas dichas villas e lugares siempre nos han servido para las neçesidades que se nos han ofreçido ..." ${ }^{9}$. Por la información de dicho servicio de 1538 sabemos que el importe total oficial ascendía a unos nueve millones de maravedies, cifra en la que se evaluaban los 1.000 galeotes con los que anualmente debian servir los pecheros de behetrías. A esta cantidad se sumaba el 1,5 por 100 en concepto de gasto por cobro y gestión del impuesto.

En la práctica las cantidades reales siempre fueron inferiores; tanto Carlos I como Felipe II y sus sucesores solían efectuar ciertas "bajas"

\section{CUADRO I}

1. Para Diego de Gamarra, que prestó 6.592 .000 maravedíes

al contador Alonso de Baeza, de principal

6.592 .000

2. Ídem, pago de intereses

723.965

3. Salarios a los procuradores de las merindades

36.000

4. Rebaja del $0,7 \%$ sobre el $1,5 \%$ inicial

72.000

TOTAL

7.423 .965 498.

- Ulloa, M., La hacienda Real de Castilla en el reinado de Felipe II, Madrid, 1986, pág.

7 Carande, R., Carlos Vy sus banqueros, Barcelona 1990, II, págs. 561-562. 1538.

\& AGS, Escribanía Mayor de Rentas, leg. 287, receptoria del servicio de galeotes, año

9 Ibidem, Merindad de Burgos. 
atendiendo a "que los vezinos estan fatigados e neçesitados". En 1538 los nueve millones de maravedies iniciales se convirtieron en 7.352.000, y el 1,5 por 100 de gastos de recaudación quedó reducido al 0,8 por $100^{10}$; con su importe la monarquia acostumbró devolver préstamos y pagar asientos ${ }^{11}$; concretamente sobre el servicio de 1538 se cargaron los siguientes gastos ${ }^{12}$ (ver Cuadro I).

De lo que no cabe duda, por la documentación manejada en este trabajo, es que desde el reinado de Felipe II el servicio de los galeotes de behetría estaba plenamente configurado, convirtiéndose en una renta habitual de la hacienda castellana y con unas características técnicas que apenas si evolucionaron en el siglo XVII: el montante final fue de unos siete millones de maravedies y la vigencia del servicio de siete años, aunque con frecuencia la monarquía exigió el pago en un solo año por cuatrimestres, concediendo a cambio sustanciales rebajas como hemos señalado.

Durante el siglo Xvi la geografía fiscal del servicio de galeotes giraba en torno a las trece merindades en que se dividian las behetrías: merindades orientales (Burgos, Candemuño, Villadiego, Castrojeriz, Bureba, Rioja y Silos) y merindades occidentales (Campos, Saldaña, Carrión, Monzón, Pernia y Cerrato) ${ }^{13}$; tal división obedeció tanto a criterios geográficos como de organización fiscal (el servicio, en la realidad, se distribuía mediante dos cartas de repartimiento, una encabezada por la merindad de Burgos y otra por la de Campos, con liquidación final independientes, aunque centralizada en Burgos a cargo de un contador de la real hacienda) ${ }^{14}$. Veamos algunos datos a partir del repartimiento de 1538, que confirman los publicados por Ulloa para el reinado de Felipe II (ver Cuadro II).

Por los repartimientos del siglo XVII sabemos que las modificaciones operadas en el servicio de galeotes fueron escasas, aunque se observa una clara tendencia degenerativa en la calidad de la documentación, que tendrá su colofón en el servicio de 1702 cuando parte de las villas de la merindad de Burgos dejen de asentarse en los cuadernos de repartimiento.

10 Ibídem.

11 AGS, Consejo y Juntas de Hacienda, leg. 19, expedientes 191 y 192, asiento con Diego de Gamarra sobre el servicio de galeotes.

12 AGS, Escribania Mayor de Rentas, leg. 287.

13 UlLoA, M., obra citada, pág. 498.

14 AGS, Escribanía Mayor de Rentas, leg. 287. 


\section{CUADRO ॥}

Merindades Orientales

Burgos

Candemuño

Villadiego

Castrojeriz

Bureba

Santo Domingo de Silos

20

Rioja

Merindades Occidentales

Campos

Saldaña

Carrión

Monzón

Pernia

Cerrato

Los servicios siguiéronse repartiendo cada siete años y con la cantidad habitual de siete millones de maravedies concedidos por los representantes de las behetrías reunidos en Santa María del Campo y Becerril; en la práctica tal cantidad nunca se cobró en su integridad, viéndose continuamente mermada por bajas que se generalizaron en el reinado de Carlos II bajo los habituales pretextos de pobreza y decadencia de la población sujeta a contribuir: 
Fiscalidad y población pechera en tierra de Behetrias...

CUADRO III

\begin{tabular}{|c|c|c|c|}
\hline MERINDAD & A & B & c \\
\hline Monzón y Pernia ... & 468.135 & 485.305 & 522.985 \\
\hline Saldaña $\ldots \ldots \ldots \ldots \ldots \ldots \ldots \ldots$ & 151.500 & 151.460 & 180.310 \\
\hline Cerrato ........... & 399.060 & 416.120 & 480.760 \\
\hline Campos & 594.760 & 606.000 & 729.470 \\
\hline Carrión & 521.160 & 533.785 & 606.900 \\
\hline Candemuño & 392.880 & 397.940 & 470.050 \\
\hline Burgos & 267.130 & 283.810 & 144.547 \\
\hline Villadiego $\ldots \ldots \ldots \ldots \ldots \ldots \ldots \ldots$ & 264.620 & 282.800 & 332.550 \\
\hline Castro-Treviño ... & 938.505 & 954.450 & 1.124 .550 \\
\hline Castro-Páramos & 334.715 & 341.380 & 398.650 \\
\hline Rioja .. & 77.780 & 78.780 & 90.440 \\
\hline Santo Domingo de Silos ... & 305.010 & 307.040 & 358.190 \\
\hline Bureba .. & 219.350 & 193.920 & 223.720 \\
\hline TOTAL $\ldots \ldots \ldots \ldots \ldots \ldots \ldots \ldots$ & 4.957 .835 & 5.055 .010 & 5.691 .082 \\
\hline
\end{tabular}

Nota: $A=$ Repartimiento de 1688. $B=$ Repartimiento de 1695. $C=$ Repartimiento de 1702.

\section{EL SERVICIO DE GALEOTES: ALGUNAS CONCLUSIONES DEMOGRÁFICAS}

\section{A) Merindades de Monzón y Pernia}

Originariamente eran dos demarcaciones fiscales independientes que a partir de los recuentos de 1695 y 1702 aparecen unidas. Comprendia un 
total de 22 núcleos, donde destacaban por su potencial demográfico las villas de Villasarracino (79 vecinos en 1688 ), Bahillo $(44,5)$ y Villamoronta $(37,5)$; el resto de los asentamientos oscilaban entre los $15-29$ vecinos, salvo $\mathrm{Na}$ veros con nueve, Olmos siete y Villacuende ocho. La evolución demográfica global de ambas merindades sigue la norma general observada en el resto de las demarcaciones estudiadas: un ligero crecimiento entre los recuentos de 1688 y 1695 ( 3,8 por 100$)$ y una caída poblacional más acusada en el servicio de 1702 (94,9 por 100 respecto 1688$)$.

Los mayores incrementos detectados se circunscriben a las villas y lugares de menor tamaño; en efecto, casi todos los que presentan recuentos inferiores a 15 vecinos observaron crecimientos muy notables, destacando el caso de Calzada con un 31, 2 por 100 entre 1688 y 1702. En cualquier caso todas estas villas obtuvieron saldos positivos medios en torno al 10-20 por 100. En los lugares con potenciales demográficos superiores a los 20 vecinos la tendencia fue a crecimientos menores: 3-8 por 100 en los dos primeros servicios de 1688 y 1695, para luego sufrir pérdidas del 4-7 por 100 en el recuento de 1702 . Encontramos, no obstante, lugares con crecimientos excepcionales para el período estudiado: Calzada $(31,2)$, Gozón (20), Olmos de Río Pisuerga $(22,2)$ y Villacuende $(20)$; en sentido contrario: Villamoronta $(-25$ por 100$)$ y Villamorco $(-47)$.

\section{B) Merindad de Saldaña}

Con 18 núcleos, esta merindad poco poblada en su conjunto (sólo 150 vecinos en 1695) presenta un crecimiento constante aunque muy limitado: 0,6 por 100 (1688-1695) y 1 por 100 (1695-1702). Por la extremada debilidad demográfica de sus villas y lugares (ninguno de ellos superaba los 20 vecinos), las tendencias observadas presentan oscilaciones y comportamientos muy diversos; nos encontramos con lugares de enorme estabilidad como Ayuela, Villabasta y Villanuño, que no vieron modificada su población pechera durante 14 años, otros sufrieron hundimientos agudísimos: Renedo $(-150$ por 100$)$, Retuerta $(-100)$, Villasur $(-50)$, La Serna $(-33)$ y Portillejo $(-22$ por 100$)$ y, en menor medida, incrementos como Poza $(36,8$ por 100), Congosto (25) y Moslares (16,7).

\section{C) Merindad de Cerrato}

La merindad de Cerrato contaba con 13 villas y lugares de tamaño medio y alto (23-60 vecinos), destacando Torquemada con 130-142 vecinos. 


\section{CUADRO IV. EVOLUCIÓN DE LA POBLACIÓN PECHERA}

\begin{tabular}{|c|c|c|c|}
\hline MERINDAD & A & B & c \\
\hline Monzón y Pernia & 462,5 & 480,5 & 439,0 \\
\hline Saldaña ....... & 149,0 & 150,0 & 151,5 \\
\hline Cerrato...$\ldots \ldots \ldots \ldots$ & 386,0 & 412,0 & 404,0 \\
\hline Campos & 588,0 & 600,0 & 613,0 \\
\hline Carrión $\ldots \ldots \ldots$ & 526,0 & 528,5 & 510,0 \\
\hline Burgos $\ldots \ldots \ldots \ldots \ldots \ldots \ldots \ldots$ & 264,5 & 281,0 & $134,0^{1}$ \\
\hline Candemuño ... & 382,0 & 394,0 & 395,0 \\
\hline Villadiego & 262,0 & 280,0 & 279,5 \\
\hline Castro (por Treviño) & 928,5 & 945,0 & 945,0 \\
\hline Castro (Páramos) & 331,5 & 338,0 & 335,0 \\
\hline Rioja $\ldots \ldots \ldots \ldots \ldots \ldots \ldots \ldots$ & 77,0 & 78,0 & 76,0 \\
\hline Santo Domingo de Silos ........ & 301,5 & 304,0 & 301,0 \\
\hline Bureba ...... & 217,5 & 192,0 & 188,0 \\
\hline \multicolumn{4}{|l|}{$\begin{array}{l}1 \text { La caída poblacional es debida } \\
\text { incluidas en el repartimiento del } \\
\text { Nota: A) Repartimiento de } 1688 \\
\text { B) Repartimiento de } 1695 \\
\text { C) Repartimiento de } 1702\end{array}$} \\
\hline
\end{tabular}

En conjunto esta demarcación de behetría presentó un saldo positivo entre 1688 y 1702 del 4,6 por 100 , aunque el máximo crecimiento lo obtuvo entre los servicios de 1688 y 1695 con el 6,7 por 100 .

Por lo común, los mayores incrementos se observaron en los lugares menos poblados (nunca por encima de los seis vecinos): Valdeolmillos (50 por 100), Torrepadre $(31,2)$, Villahoz $(18,2)$ y, sobre todo, Villaverde de Mojina 


\section{CUADRO V. EVOLUCIÓN PORCENTUAL DE LA POBLACIÓN PECHERA}

\begin{tabular}{|c|c|c|c|c|}
\hline MERINDAD & A & B & c & D \\
\hline Monzón y Pernia & 22 & 100,0 & 103,8 & 94,9 \\
\hline Saldaña & 18 & 100,0 & 100,6 & 101,6 \\
\hline Cerrato $\ldots \ldots \ldots \ldots \ldots \ldots \ldots$ & 13 & 100,0 & 106,7 & 104,6 \\
\hline Campos .. & 8 & 100,0 & 102,0 & 104,2 \\
\hline Carrión & 14 & 100,0 & 100,4 & 96,9 \\
\hline Burgos $\ldots \ldots \ldots \ldots \ldots \ldots \ldots$ & 29 & 100,0 & 106,2 & $50,6^{1}$ \\
\hline Candemuño $\ldots . . \ldots \ldots \ldots \ldots$ & 23 & 100,0 & 103,1 & 103,4 \\
\hline Villadiego & 45 & 100,0 & 106,8 & 106,6 \\
\hline Castro (Treviño) .............. & 30 & 100,0 & 101,7 & 101,7 \\
\hline Castro (Páramos) .. & 24 & 100,0 & 101,9 & 101,0 \\
\hline Rioja & 4 & 100,0 & 101,2 & 98,7 \\
\hline Santo Domingo de Silos ...... & 20 & 100,0 & 100,8 & 99,8 \\
\hline Bureba $\ldots \ldots \ldots \ldots \ldots \ldots \ldots$ & 28 & 100,0 & 88,2 & 86,4 \\
\hline
\end{tabular}

1 La aguda caida porcentual se produjo porque dejan de contabilizarse en el repartimiento de 1702 un total de 14 villas y lugares.

Nota: A) Número de villas y lugares

B) Porcentaje repartimiento de 1688

C) Idem repartimiento 1695

D) Idem repartimiento 1702

con un 64,3; los núcleos más poblados (Torquemada y Villamediana) crecieron a un ritmo menor y siempre con mayor énfasis entre 1688 y 1695: Torquemada crece el 8,45 por 100 entre 1688 y 1695, sufre una pérdida del 7,6 por 100 entre 1695 y 1702, logrando en conjunto un saldo positivo del 1,52 por 100 
Fiscalidad y población pechera en tierra de Behetrias...

entre 1688 y 1702; Villamediana creció el 11,8 por 100 en los dos primeros recuentos para estabilizarse en el periodo final de 1695-1702.

D) Campos

Con sólo ocho núcleos de población era proporcionalmente la merindad más densamente poblada: todas las villas presentaban vecindades superiores a los 40 vecinos, destacando (con datos del censo de 1688) Frechilla 172 vecinos, Becerril 121 y Fuentes de D. Bermudo 85. Todos los núcleos presentaron crecimientos netos, salvo Frechilla. Veamos el siguiente cuadro que refleja las tendencias observadas:

VILLALUGAR

1688-1695

1695-1702

1688-1702

Autilla $-4,1$

3,9

0,0

Baquerin

7,8

$-5,6$

Becerril

0,0

6,9

6,9

Capillas

9,0

$-2,3$

6,9

Frechilla

$-1,2$

$-4,9$

$-6,2$

Fuentes de D. Bermudo

6,5

2,1

8,6

Palacios de Campos

0,0

0,0

0,0

Villarramiel

6,1

18,3

23,3

E) Merindad de Carrión

La merindad de Carrión -con 14 núcleos poblados- presentó en conjunto un saldo negativo del 3,1 por 100 para el período estudiado; son 
villas con potencial demográfico medio de $15-30$ vecinos, salvo Cisneros con 120 para 1688, Boadilla de Rioseco con 100 y Cervatos de la Cueza con 86 vecinos. La tendencia puede sintetizarse de la siguiente manera:

\begin{tabular}{|c|c|c|c|}
\hline VILLAVLUGAR & $1688-1695$ & $1695-1702$ & $1688-1702$ \\
\hline Abastas & 21,1 & 5,0 & 25,0 \\
\hline Abastillas & 23,8 & $-5,0$ & 20,0 \\
\hline Añoza & 18,9 & $-23,0$ & 0,0 \\
\hline Arroyo & 5,8 & 15,0 & 20,0 \\
\hline Boadilla de Rioseco & $-4,2$ & $-10,0$ & $-15,0$ \\
\hline Cervatos de la Cueza ............. & $-10,0$ & $-11,0$ & $-23,0$ \\
\hline Cisneros $\ldots \ldots \ldots \ldots \ldots$ & $-9,5$ & 13,4 & 5,1 \\
\hline Mazuecos $\ldots \ldots \ldots \ldots \ldots \ldots$ & $-5,0$ & 0,0 & $-5,0$ \\
\hline Población de Arroyo .............. & 0,0 & $-8,7$ & $-8,7$ \\
\hline Riberos de la Cueza & 9,0 & 12,0 & 20,0 \\
\hline S. Román de la Cuba $\ldots . . \ldots \ldots$ & 16,7 & -9.9 & 8,4 \\
\hline$\ldots \ldots \ldots \ldots \ldots$ & 4,4 & $-26,0$ & $-20,0$ \\
\hline
\end{tabular}

\section{F) Merindad de Burgos}

Con 29 villas y lugares la merindad de Burgos sólo presenta información demográfica para el período 1688-1695 (en el repartimiento de 1702 faltan 14 entidades de población); se trata de lugares con vecindades muy débiles -19 núcleos poseían en 1688 menos de 10 vecinos pecheros- 
Fiscalidad y población pechera en tierra de Behetrías...

que en ningún caso superaron los 30 vecinos. Estas características estructurales conducian a contrastes demográficos muy acusados: lugares como Temiño (1,5 vecinos) y Albillos $(5,5)$ duplicaron su poblacón entre 1688 y 1702, otros con acusados hundimientos poblacionales como Rioseras $(-33$ por 100$)$, Hurones $(-50)$ y Celada de la Torre (-60 por 100$)$. Lo que es evidente, de nuevo en este caso, que los mayores incrementos se produjeron entre 1688 y 1695.

\section{G) Merindad de Candemuño}

Presenta un crecimiento global del 3,4 por 100 , aunque los mayores incrementos también se produjeron entre 1688-1695 con un 3,1 por 100; las villas y lugares (un total de 23) representaban un tamaño medio predominante en torno a los 15-23 vecinos, con unos máximos en Presencio (54), Mahamud (40) y Santa María del Campo (35) y unos mínimos en Villafuentes (1 vecino), Montuenga (3) y Villanueva de las Carretas (3). Algunos ejemplos pueden ser ilustrativos de las tendencias demográficas:

\begin{tabular}{|c|c|c|c|}
\hline VILLALUGAR & $1688-1695$ & $1695-1702$ & $1688-1702$ \\
\hline Cabia ... & 15,0 & 4,7 & 19,0 \\
\hline Cael & $-28,0$ & $-29,0$ & $-64,0$ \\
\hline Celada del Camino $\ldots \ldots \ldots \ldots \ldots$ & 11,4 & $-2,9$ & 8,8 \\
\hline Mahamud & 0,0 & $-33,0$ & $-33,0$ \\
\hline Montuenga $\ldots \ldots \ldots \ldots \ldots \ldots \ldots$ & 0,0 & 16,7 & 16,7 \\
\hline Presencio & $-9,0$ & $-28,0$ & $-40,0$ \\
\hline Quintanillas .. & 36,7 & 11,8 & 44,1 \\
\hline Tamarón $\ldots \ldots \ldots \ldots \ldots \ldots \ldots$ & 3,4 & 14,7 & 17,6 \\
\hline Vilviestre & 6,6 & 16,7 & 22,2 \\
\hline Villamayor de Montes $\ldots . \ldots \ldots \ldots$ & $-6,7$ & 11,8 & 5,8 \\
\hline
\end{tabular}




\section{CUADRO VI. POBLACIÓN PECHERA SEGÚN COEFICIENTE VECINO/HABITANTE}

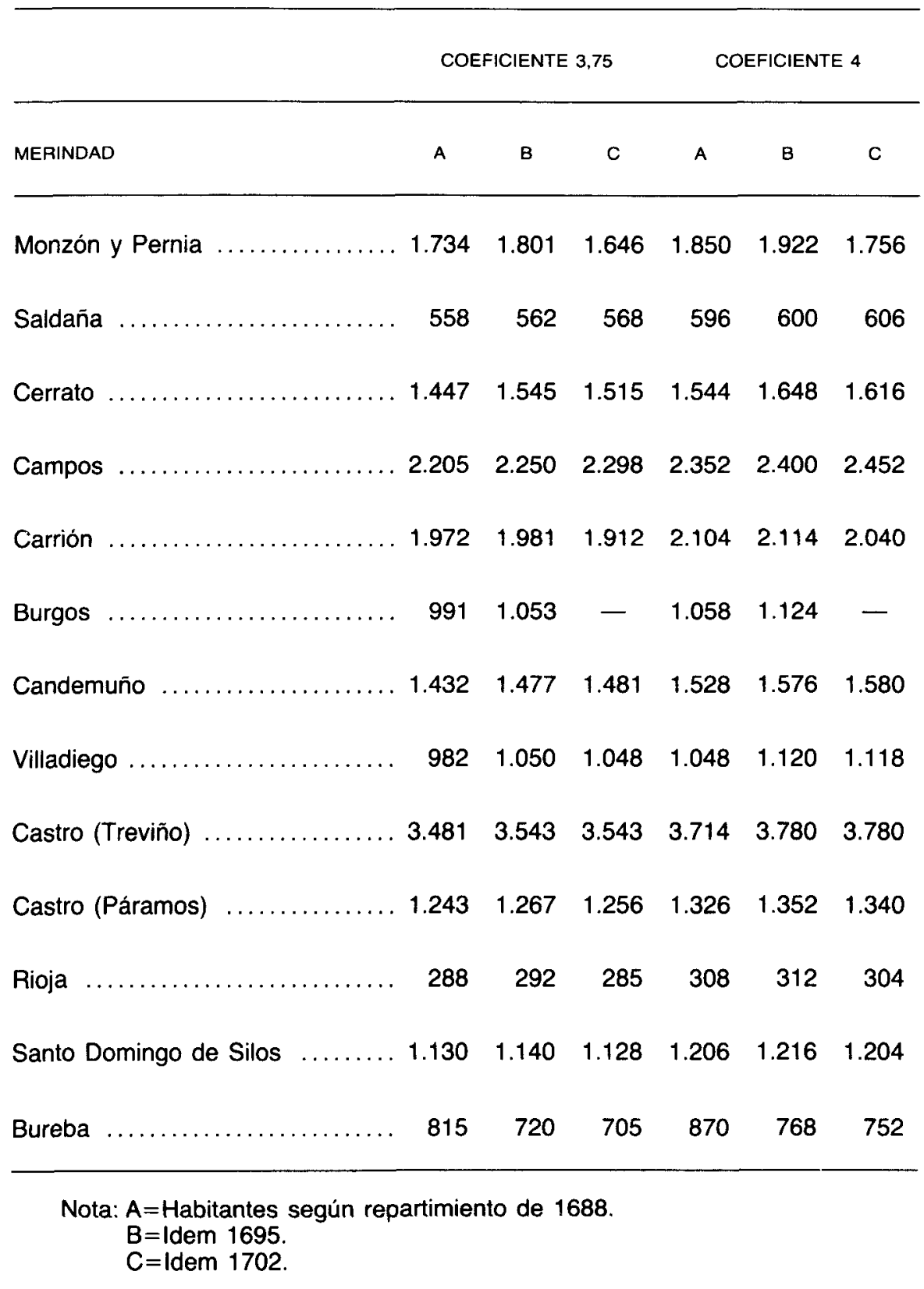




\section{H) Merindad de Villadiego}

Era la merindad con el mayor número de entidades de población (un total de 45), pero al mismo tiempo la que presentaba villas y lugares de menor entidad: 38 de ellos poseian menos de 10 vecinos pecheros y el resto en ningún caso superó los 17 vecinos. El conjunto presenta un crecimiento del 6,6 por 100 para el período estudiado, aunque - siguiento la norma general- los mayores incrementos se observaron entre 1688 y $1695(6,8$ por 100$)$.

\section{l) Merindad de Castro}

Dividida en dos entidades (Treviño y Páramos) agrupaba un total de 54 villas y lugares (30 y 24 respectivamente). Aunque presentan unos comportamientos demográficos similares (crecimiento del 1,7 por 100 en Treviño y 1 por 100 en Páramos), las características entre ambas merindades presentaban diferencias estructurales notables: Treviño era una demarcación con núcleos con vecindades medias de 22-70 pecheros y excepciones como Melgar de Fernamental (126 vecinos), Villasandino (78) y Lantadilla (66); sólo el 20 por 100 de sus lugares eran menores de 10 vecinos. Páramos en ningún caso presentaba villas con vecindades superiores a 48 pecheros, y el número de entidades de población inferiores a 10 vecinos suponia el 30 por 100 .

\section{J) Merindad de Rioja}

Sólo comprendía cuatro lugares: Tripiana, Cerratón de Rioja, Manjarrés y Villar de Torre. El conjunto observó un crecimiento del 1,2 por 100 para el periodo $1688-1695$ y una pérdida de 1,3 para el total del período estudiado. El comportamiento demográfico particular fue el siguiente: 


\begin{tabular}{lccc}
\hline \multicolumn{1}{c}{ LUGAR } & $1688-1695$ & $1695-1702$ & $1688-1702$ \\
\hline Cerratón de Rioja $\ldots \ldots \ldots \ldots \ldots \ldots$ & 3,3 & 0,0 & 3,3 \\
Manjarrés $\ldots \ldots \ldots \ldots \ldots \ldots \ldots \ldots$ & - & 0,0 & 0,0 \\
Tripiana $\ldots \ldots \ldots \ldots \ldots \ldots \ldots \ldots \ldots$ & $-14,0$ & 0,0 & $-14,0$ \\
Villar de Torre $\ldots \ldots \ldots \ldots \ldots \ldots \ldots$ & 21,1 & $-12,0$ & 11,8 \\
\hline
\end{tabular}

K) Merindad de Santo Domingo de Silos

Abarcaba un total de 20 entidades de población con vecindades medias de 15-30 pecheros, aunque encontramos también lugares con menos de 10 vecinos que suponian el 40 por 100 del total. Durante el período estudiado la población apenas si varió: crecimiento del 0,8 por 100 en 1688-1695 y una pérdida del 0,2 por 100 en el intervalo 16881702.

\section{L) Merindad de Bureba}

Es la única merindad de behetría que presenta el mayor saldo negativo de la población pechera: entre 1688 y 1695 perdió un 11,8 por 100 que se eleva al 13,6 para el total del periodo estudiado. Sólamente crecieron seis lugares todos ellos de poblaciones muy reducidas (ninguno superó los ocho vecinos). Veamos el comportamiento de algunos de ellos: 
Fiscalidad y población pechera en tierra de Behetrias...

\begin{tabular}{|c|c|c|c|}
\hline VILLALUGAR & $1688-1695$ & $1695-1702$ & $1688-1702$ \\
\hline Aguilar de Bureba $\ldots \ldots \ldots \ldots \ldots$ & $-17,0$ & 0,0 & $-17,0$ \\
\hline Barrios de Bureba .............. & 33,0 & 0,0 & 33,0 \\
\hline Calzada ... & $-200,0$ & 0,0 & $-200,0$ \\
\hline Carcedo . & $-67,0$ & 33,3 & $-11,0$ \\
\hline Cubo $\ldots \ldots \ldots \ldots \ldots \ldots \ldots \ldots$ & -64 & 6,6 & $-53,0$ \\
\hline Hermosilla...$\ldots \ldots \ldots \ldots \ldots$ & $-300,0$ & 0,0 & $-300,0$ \\
\hline Lermilla ... & 25,0 & $-33,0$ & 0,0 \\
\hline Quintana de Bureba ............. & $-67,0$ & 40,0 & 0,0 \\
\hline Rublacedo de Abajo ............. & 0,0 & $-60,0$ & $-60,0$ \\
\hline
\end{tabular}

En definitiva, los recuentos de vecinos pecheros de los censos de galeotes de 1688, 1695 y 1702 presentan todos los problemas de este tipo de fuente demográfica; especialmente las sospechas sobre su calidad proceden de su carácter fiscal y, sobre todo, porque fueron recuentos efectuados sin ningún control de la hacienda real. En efecto, llaman la atención varios hechos: tienden a disminuir las poblaciones en el último de los recuentos estudiados, los empadronadores fueron los propios concejos que a su vez eran los que designaban los procuradores en las juntas generales de las tierras de behetrias y, en general, la información demográfica contenida en los repartimientos es tan limitada que impide una valoración y análisis mínimamente satisfactorios. No obstante, estos tres recuentos pueden constituir un elemento a tener en cuenta en futuros trabajos, bien para admitirlos, bien para corregirlos o, incluso, rechazarlos. 
Fiscalidad y población pechera en tierra de Behetrias...

\section{Apéndice I}

1. Población Pechera (por merindades y localidades)

Nota: A) Repartimiento de 1688

B) Repartimiento de 1695

C) Repartimiento de 1702 
Fiscalidad y población pechera en tierra de Behetrias...

MERINDADES DE MONZÓN Y PERNIA

A

B

C

Villasarracino

79,0

86,0

80,0

Villahermoso

29,0

30,0

29,5

Osornillo

18,0

25,0

18,5

San Llorente de la Vega

10,0

8,0

10,0

Fuente-Andrino

11,0

13,0

13,0

Naveros

9,0

14,5

10,5

Olmos de Río Pisuerga

7,0

10,5

9,0

Bárcena

17,0

20,0

19,5

Colmenares

11,0

9,0

10,0

Dehesa de Montejo

15,0

13,0

12,5

Calzada

16,5

26,5

24,0

Quintanilla de la Cueza

15,5

9,0

12,0

Bustillo de Potroviejo

26,5

27,5

27,0

Villacuende

8,0

9,5

10,0

Villamoronta

37,5

38,0

30,0

Villasavariego

27,0

25,0

24,0

Robladillo

22,0

23,0

16,5

Villamorco

25,0

23,0

17,0

Gozón

12,0

14,0

15,0

Bahillo

44,5

44,0

36,0

Calzadilla de la Cueza

12,0

12,0

15,0

Ravinos

10,0 


\begin{tabular}{|c|c|c|c|}
\hline MERINDAD DE SALDAÑA & A & B & c \\
\hline Congosto $\ldots \ldots \ldots \ldots \ldots \ldots \ldots$ & 6,0 & 5,5 & 8,0 \\
\hline Villovela ........... & 18,5 & 19,0 & 17,5 \\
\hline Polvorosa $\ldots . . .$. . & 8,0 & 7,0 & 7,5 \\
\hline Renedo $\ldots . . . \ldots \ldots \ldots \ldots \ldots$ & 10,0 & 7,0 & 4,0 \\
\hline Tabanera & 12,0 & 10,5 & 11,5 \\
\hline Ayuela & 10,0 & 10,5 & 10,0 \\
\hline Villabasta & 6,0 & 6,0 & 6,0 \\
\hline Villaproviano & 10,0 & 7,0 & 11,0 \\
\hline Portillejo ......... & 5,5 & 5,5 & 4,5 \\
\hline Aldea ....... & 4,0 & 4,0 & 3,0 \\
\hline$\ldots \ldots \ldots \ldots \ldots \ldots$ & 12,0 & 9,0 & 9,0 \\
\hline Villasur $\ldots \ldots \ldots \ldots \ldots \ldots \ldots \ldots$ & 6,0 & 4,0 & 4,0 \\
\hline Poza.......... & 12,0 & 20,0 & 19,0 \\
\hline Moslares $\ldots \ldots \ldots \ldots \ldots \ldots \ldots$ & 2,5 & 2,5 & 3,0 \\
\hline Retuerta & 3,0 & 2,5 & 1,5 \\
\hline Villanuño $\ldots \ldots \ldots \ldots \ldots \ldots \ldots$ & 6,0 & 6,5 & 6,0 \\
\hline Renedo del Monte.... & 4,0 & 4,5 & 9,5 \\
\hline La Puebla. & 13,5 & 19,0 & 16,5 \\
\hline
\end{tabular}


Fiscalidad y población pechera en tierra de Behetrías...

\begin{tabular}{|c|c|c|c|}
\hline MERINDAD DE CERRATO & A & $B$ & $\mathrm{c}$ \\
\hline Torquemada ............ & 130,0 & 142,0 & 132,0 \\
\hline Villamediana $\ldots \ldots \ldots \ldots \ldots \ldots$ & 60,0 & 68,0 & 68,0 \\
\hline Peral $\ldots \ldots \ldots \ldots \ldots \ldots \ldots \ldots \ldots$ & 12,0 & 9,0 & 9,0 \\
\hline Valdeolmillos ....... & 4,0 & 5,0 & 8,0 \\
\hline Alba de Cerrato $\ldots \ldots \ldots \ldots \ldots$ & 13,0 & 16,0 & 14,0 \\
\hline Esguevillas & 32,0 & 30,0 & 25,0 \\
\hline Bertavillo .... & 34,0 & 33,0 & 34,0 \\
\hline Castrillo de Onielo & 26,0 & 25,0 & 25,0 \\
\hline Antigüedad $\ldots \ldots \ldots \ldots$ & 17,0 & 14,0 & 17,0 \\
\hline Royuela .... & 23,0 & 24,0 & 24,0 \\
\hline Torrepadre .......... & 5,5 & 7,0 & 8,0 \\
\hline Villaverde de Mojina...$\ldots \ldots \ldots \ldots$ & 2,5 & 3,0 & 7,0 \\
\hline Villahoz & 27,0 & 36,0 & 33,0 \\
\hline MERINDAD DE CAMPOS & A & B & $\mathrm{C}$ \\
\hline Becerril & 121,0 & 121,0 & 130,0 \\
\hline Frechilla & 172,0 & 170,0 & 162,0 \\
\hline Fuentes de D. Bermudo .......... & 85,0 & 91,0 & 93,0 \\
\hline Villarramiel & 46,0 & 49,0 & 60,0 \\
\hline Capillas & 40,0 & 44,0 & 43,0 \\
\hline Palacios de Campos & 38,0 & 38,0 & 38,0 \\
\hline Baquerín & 35,0 & 38,0 & 36,0 \\
\hline Autilla del Pino $\ldots \ldots \ldots \ldots \ldots \ldots$ & 51,0 & 49,0 & 51,0 \\
\hline
\end{tabular}


Boadilla de Rioseco

100,0

96,0

87,0

Cisneros

120,5

110,0

127,0

Cervatos de la Cueza

86,0

78,0

70,0

Mazuecos

31,5

30,0

30,0

Pozo de Urama

27,5

32,0

27,0

San Román de la Cuba

32,5

39,0

35,5

Villaicón

32,5

34,0

27,0

Arroyo

8,0

8,5

10,0

Población de Arroyo

25,0

25,0

23,0

Añoza

15,0

18,5

15,0

Abastillas

8,0

10,5

10,0

Abastas

15,0

19,0

20,0

Villanueva del Rebollar

14,5

17,0

16,0

Riberos de la Cueza

10 ,

11,0

12,5 
Fiscalidad y población pechera en tierra de Behetrias...

MERINDAD DE BURGOS

A

B

C

Buniel

20,0

24,0

25,0

Tobes y Raedo

6,0

7,0

8,0

Villayerno-Morquillas

7,0

7,0

8,0

Celadilla-Sotobrin

14,0

16,0

15,0

Quintanaortuño

3,5

Melgosa

2,0

4,0

4,0

Temiño

1,5

2,0

3,0

Albillos

5,5

2,0

3,0

Rioseras

30,0

10,0

11,0

Ubierna y San Martín

9,0

29

19,0

Hurones

9,0

8,0

9,0

Celada de la Torre

8,0

6,0

6,0

Sotragero

10,5

6,0

5,0

Castil de Cerracín

5,5

11,0

11,0

Mata Sobresierra

1,0

6,0

6,0

Maruéllar

10,0

Villanueva de Río-Ubierna

24,0

Modubar de la Emparedada

6,0

2,0

1,0

Cojobar

6,0

Modubar de la Cuesta

11,0

Umienta (?)

6,5

Quintanilla Morocisla

2,0

Olmosalbos

1,5

Robledo Cavetemino (?)

7,0

Gradilla de la Polera

8,0

Riocerezo

25,0

Nidáguila

5,5

Quintana de las Torres

19,5

Marmellar

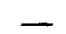

23,0

7,0

4,0

7,0

4,0

2,0

2,0

9,0

7,0

28,0

7,0

20,0

21,0 


\begin{tabular}{|c|c|c|c|}
\hline MERINDAD DE CANDEMUÑO & A & B & $\mathrm{c}$ \\
\hline Villafuentes $\ldots . . . \ldots \ldots \ldots \ldots \ldots$ & 1,0 & 1,0 & 1,0 \\
\hline Villar Gómez & 10,0 & 10,0 & 11,0 \\
\hline Cogollos $\ldots \ldots \ldots \ldots \ldots \ldots \ldots \ldots$ & 15,0 & 17,0 & 18,0 \\
\hline Valdorros $\ldots . . . \ldots \ldots \ldots \ldots \ldots$ & 10,0 & 10,0 & 10,0 \\
\hline Montuenga $\ldots \ldots \ldots \ldots \ldots \ldots \ldots$ & 3,0 & 3,0 & 6,0 \\
\hline Villamayor de Montes $\ldots \ldots \ldots \ldots$ & 32,0 & 30,0 & 34,0 \\
\hline$\ldots \ldots \ldots \ldots$ & 23,0 & 18,0 & 14,0 \\
\hline Arenillas de Candenuño .......... & 2,0 & 3,0 & 4,0 \\
\hline Mazuelo $\ldots \ldots \ldots \ldots \ldots \ldots \ldots$ & 10,0 & 9,0 & 10,0 \\
\hline Cayuela & 5,0 & 2,0 & 4,0 \\
\hline Villamiel $\ldots$ & 4,0 & 4,0 & 8,0 \\
\hline Cabia ...... & 17,0 & 20,0 & 21,0 \\
\hline Quintanillas, Las ... & 19,0 & 30,0 & 34,0 \\
\hline Villagutierre $\ldots \ldots \ldots \ldots \ldots \ldots$ & 5,0 & 5,0 & 7,0 \\
\hline Vilviestre $\ldots \ldots \ldots \ldots \ldots \ldots \ldots$ & 14,0 & 15,0 & 18,0 \\
\hline Iglesias $\ldots \ldots \ldots \ldots \ldots \ldots \ldots \ldots$ & 40,0 & 44,0 & 48,0 \\
\hline Tamarón $\ldots \ldots \ldots \ldots \ldots \ldots \ldots$ & 14,0 & 14,5 & 17,0 \\
\hline Celada del Camino...$\ldots \ldots \ldots \ldots$ & 15,5 & 17,5 & 17,0 \\
\hline Villadelmiro $\ldots . . . \ldots \ldots \ldots \ldots \ldots$ & 10,0 & 12,0 & 13,0 \\
\hline Villanueva de las Carretas ....... & 3,0 & 3,0 & 3,0 \\
\hline Presencio & 54,0 & 50,0 & 39,0 \\
\hline Mahamud................. & 40,0 & 40,0 & 30,0 \\
\hline Santa María del Campo & 35,0 & 36,0 & 38,0 \\
\hline
\end{tabular}


Fiscalidad y población pechera en tierra de Behetrías..

B

C

\begin{tabular}{|c|c|c|c|}
\hline Humada & 6,0 & 7,0 & 6,5 \\
\hline Rebolledo de Traspeña $\ldots . \ldots \ldots$. & 4,0 & 6,0 & 4,0 \\
\hline Villamartín $\ldots \ldots \ldots \ldots \ldots \ldots \ldots \ldots$ & 6,0 & 8,0 & 7,0 \\
\hline$\ldots \ldots \ldots, \ldots, \ldots, \cdots$ & 4,0 & 4,0 & 4,5 \\
\hline Rebolledo de La Torre.....$\ldots \ldots$ & 11,0 & 10,0 & 11,0 \\
\hline Alba Castro y Valtierra ........... & 8,0 & 8,0 & 8,0 \\
\hline Castrecias $\ldots \ldots \ldots \ldots \ldots \ldots \ldots$ & 5,5 & 7,0 & 6,5 \\
\hline Renedo de la Escalera ........... & 5,0 & 4,0 & 5,5 \\
\hline$\ldots \ldots \ldots \ldots \ldots \ldots \ldots \ldots \ldots \ldots$ & 4,0 & 4,0 & 5,0 \\
\hline Fuencaliente & 6,0 & 7,0 & 6,0 \\
\hline$\ldots \ldots \ldots \ldots$ & 2,5 & 2,0 & 3,0 \\
\hline Villaescobedo & 4,0 & 3,0 & 4,5 \\
\hline Quintanas $\ldots \ldots \ldots \ldots \ldots \ldots \ldots$ & 5,5 & 8,0 & 6,5 \\
\hline Mundilla $\ldots \ldots \ldots \ldots \ldots \ldots \ldots \ldots$ & 4,5 & 3,0 & 4,0 \\
\hline Pedrosa $\ldots \ldots \ldots \ldots \ldots \ldots \ldots \ldots$ & 4,5 & 3,0 & 4,5 \\
\hline Solanas $\ldots \ldots \ldots \ldots \ldots \ldots \ldots \ldots$ & - & 2,0 & 2,5 \\
\hline Fuencaliente de Puerta...$\ldots \ldots \ldots$ & 3,0 & 2,5 & 3,5 \\
\hline Corralejo $\ldots \ldots \ldots \ldots \ldots \ldots \ldots \ldots$ & 2,5 & 1,5 & 2,5 \\
\hline$\ldots \ldots \ldots \ldots, \ldots, \ldots$ & 7,5 & 9,0 & 8,0 \\
\hline Nuez de Urbel, La $\ldots . \ldots \ldots \ldots \ldots$ & 6,0 & 7,0 & 6,5 \\
\hline$\ldots \ldots \ldots \ldots \ldots \ldots$ & 4,0 & 3,0 & 4,5 \\
\hline$\ldots \ldots, \ldots \ldots \ldots$ & 3,0 & 3,0 & 3,5 \\
\hline Hormazuela,$\ldots \ldots \ldots \ldots \ldots \ldots$ & 3,0 & 3,0 & 3 , \\
\hline Coculina .... & 9,0 & 11,0 & 10,0 \\
\hline$\ldots \ldots \ldots \ldots \ldots \ldots$, & 5,0 & 4,0 & $4, \mathrm{C}$ \\
\hline$\ldots \ldots \ldots \ldots \ldots \ldots$ & 2,0 & 2,0 & 2,5 \\
\hline Villanueva de Puerta $\ldots . \ldots \ldots \ldots$. & 6,0 & 8,0 & 7,5 \\
\hline Villalvila $\ldots \ldots \ldots \ldots \ldots \ldots \ldots \ldots$ & 13,0 & 14,0 & 12,5 \\
\hline$\ldots \ldots \ldots, \ldots, \ldots$, & 2,5 & 2,0 & 2,5 \\
\hline Melgosa $\ldots \ldots \ldots \ldots \ldots \ldots \ldots \ldots$ & 3,0 & 2,0 & 3,0 \\
\hline Quintanilla de la Presa $\ldots \ldots \ldots \ldots$. & 3,0 & 3,0 & 2,5 \\
\hline Villahernando $\ldots \ldots \ldots \ldots \ldots \ldots$ & 3,0 & 2,0 & 3,5 \\
\hline Villaliado $\ldots \ldots \ldots \ldots \ldots \ldots \ldots$ & 8,0 & 6,0 & 8,5 \\
\hline Castromorca & 9,0 & 8,0 & 8,5 \\
\hline Olmos de la Picaza & 17,0 & 17,0 & 17,0 \\
\hline Villamayor de Treviño $\ldots \ldots \ldots \ldots$. & $11,0,0$ & $12,0,0$ & 10,0 \\
\hline Villahizán $\ldots \ldots \ldots \ldots \ldots \ldots \ldots \ldots$ & 16,0 & 19,0 & 17,0 \\
\hline Villanueva de Odra ................. & 17,0 & 21,0 & 15,5 \\
\hline Tарiа $\ldots \ldots \ldots \ldots \ldots \ldots \ldots \ldots \ldots$ & 9,0 & 11,0 & 10,5 \\
\hline$\ldots \ldots \ldots \ldots \ldots \ldots$ & 4,0 & 4,0 & 5,0 \\
\hline Sandoval de la Reina $\ldots \ldots \ldots \ldots \ldots$ & 8,0 & 11,0 & 11,0 \\
\hline Sordillos $\ldots \ldots \ldots \ldots \ldots \ldots \ldots \ldots$ & 5,0 & 6,0 & 5,5 \\
\hline Tagarrosa $\ldots \ldots \ldots \ldots \ldots \ldots \ldots$ & 1,0 & - & 一 \\
\hline Brulles (?) $\ldots \ldots \ldots \ldots \ldots \ldots \ldots$ & 1,0 & 2,0 & 2,0 \\
\hline Hormicedo $\ldots \ldots \ldots \ldots \ldots \ldots \ldots$ & - & - & - \\
\hline
\end{tabular}


Palazuelos 4,0

5,0 5,0

Judego y Villandiego

36,0

36,0

36,0

Balbases, Los

46,0

46,0

46,0

Revilla-Vallegera

31,0

31,0

31,0

Villalaco

10,0

10,0

15,0

Cordovilla

10,0

12,0

6,0

Valbuena de Río Pisuerga

2,5

2,0

4,0

Itero de la Vega

30,0

34,0

34,0

Arenillas de Río Pisuerga

42,0

45,0

45,0

Melgal de Fernamental

126,0

126,0

106,0

Valtierra de Río Pisuerga

8,0

8,0

6,0

Padilla de Arriba

33,0

30,0

30,0

Padilla de Abajo

45,0

48,0

48,0

Grijalba

22,0

22,0

22,0

Villegas y Villamorón

28,0

30,0

30,0

Sasamón

76,0

78,0

72,0

Castrillo de Murcia

40,0

42,0

42,0

Villasandino

78,0

78,0

78,0

Santoyo

54,0

56,0

75,0

Boadilla del Camino

38,0

38,0

38,0

Melgar de Yuso

10,0

8,0

8,0

Villasilos

43,0

45,0

45,0

Lantadilla

66,0

66,0

66,0

Villodre

10,0

8,0

14,0

Pedrosa de Socastro

23,0

26,0

26,0

Villamedianilla

6,0

6,0

7,0

Vallunquera

2,0

1,0

2,0

Hinestrosa

9,0

8,0

Perex

Puente Itero 
C

Hormazas, Las

30,5

34,0

34,0

Pedrosa de Río-Urbel

29,0

32,0

26,0

Cañizar de los Ajos

24,0

24,0

25,0

Santibáñez de Zarzaguda

42,0

40,0

38,0

Lodoso

14,0

15,0

13,0

Pedrosa del Páramo

12,0

12,0

12,0

Susinos

13,0

14,0

14,0

Manciles

10,0

10,0

11,0

Quintanilla de Pedro de Abarca .

4,0

5,0

4,0

San Pantaleón

3,0

4,0

3,0

Huermeces

5,0

7,0

7,0

Ruyales del Páramo

3,0

1,0

Tremellos, Los

10,0

10,0

13,0

Cítores del Páramo

6,0

9,0

8,0

Roscón Monasteruelo

11,0

12,0

13,0

Palacios de Benaver

20,0

22,0

21,0

Villorejo

20,0

20,0

21,0

Abellanosa del Páramo

14,0

16,0

18,0

Miñón

8,0

9,0

8,0

Rebolledas, Las

9,0

6,0

7,0

Zumel

9,0

8,0

9,0

Santa María de Tajadura

9,0

8,0

8,0

San Pedro Samuel

14,0

12,0

14,0

Celadas, Las

12,0

8,0

8,0 


\begin{tabular}{|c|c|c|c|}
\hline MERINDAD DE RIOJA & A & B & $c$ \\
\hline Tripiana $\ldots . . . \ldots \ldots \ldots$ & 33,0 & 29,0 & 29,0 \\
\hline Cerratón de Rioja & 29,0 & 30,0 & 30,0 \\
\hline Manjarres $\ldots \ldots \ldots \ldots \ldots \ldots \ldots$ & - & - & - \\
\hline Villar de Torre ... & 15,0 & 19,0 & 17,0 \\
\hline $\begin{array}{l}\text { MERINDAD DE SANTO DOMINGO } \\
\text { DE SILOS }\end{array}$ & A & $B$ & c \\
\hline Tordomar ........... & 14,5 & 14,5 & 15,0 \\
\hline Paules del agua ........ & 5,0 & 4,0 & 5,0 \\
\hline Pinilla de Trasmonte. & 36,0 & 30,0 & 22,5 \\
\hline Quintana Raya $\ldots \ldots \ldots \ldots \ldots \ldots$ & 15,0 & 17,0 & 18,5 \\
\hline Iglesiarrubia ....... & 6,0 & 5,0 & 5,0 \\
\hline Arauzo de Salce ... & 8,0 & 12,0 & 12,5 \\
\hline Arauzo de Torre .... & 7,0 & 8,0 & 8,0 \\
\hline Arauzo de Miel & 36,0 & 33,0 & 25,5 \\
\hline Quintanilla del Agua ............. & 13,0 & 18,0 & 17,5 \\
\hline Castrillo de Solarana ............ & 19,0 & 17,0 & 16,5 \\
\hline Nebreda & 23,0 & 16,5 & 15,0 \\
\hline Cebrecos & 12,0 & 13,0 & 15,0 \\
\hline Zacuar (?) .... & 28,0 & 28,0 & 22,5 \\
\hline Hinojar del Rey & 6,0 & 10,0 & 11,0 \\
\hline Hontoria de Valdearados ......... & 17,0 & 18,0 & 20,0 \\
\hline Cilleruelo de Arriba. & 9,0 & 8,0 & 11,0 \\
\hline Valdeande .... & 8,0 & 13,0 & 18,0 \\
\hline Quintanilla del Coco ............. & 6,0 & 8,0 & 7,0 \\
\hline Pineda de Trasmonte $\ldots \ldots \ldots \ldots$ & 17,0 & 16,0 & 16,0 \\
\hline Baños & 16,0 & 15,0 & 19,5 \\
\hline
\end{tabular}


Fiscalidad y población pechera en tierra de Beheirias...

B

c

Santa María de Ribarredonda ....

28,0

24,0

24,0

Buero de Sierra

2,0

2,0

2,0

Lermilla

3,0

4,0

3,0

Movilla

1,0

1,0

1,0

Aguilar de Bureba

14,0

12,0

12,0

Quintana-Urria

6,0

4,0

4,0

Terrazos

3,0

9,0

7,0

Rojas

5,5

8,0

8,0

Castil de Lences

2,0

Barrios de Bureba

4,0

6,0

6,0

Parte, La

1,0

Quintana Suso

2,0

1,0

-

Quintana de Bureba

5,0

3,0

2,0

Salas de Bureba

6,0

4,0

5,0

Zuñeda

22,0

22,0

4,5

Calzada

6,0

2,0

18,0

Cubo

23,0

14,0

2,0

Cameno

20,0

16,0

15,0

Carcedo

5,0

3,0

15,0

Rublacedo de Arriba

3,0

3,0

4,5

Rublacedo de Abajo

8,0

8,0

4,0

Quintanilla de Bon

4,0

8,0

5,0

Santaolalla

1,0

Valdearnedo

2,0

-

8,0

Miraveche

25,0

3,0

1,0

Reinoso

9,0

24,0

1,0

Salinillas

3,0

4,0

23,0

Hermosilla

4,0

6,0

8,0

4,0

1,0

1,0 
Fiscalidad y población pechera en tierra de Behetrías...

\section{Apéndice II}

2. Distribución del servicio de galeotes (en maravedies)

Nota: A) Servicio de 1688

B) Servicio de 1695

C) Servicio de 1702 
Fiscalidad y población pechera en tierra de Behetrias...

MERINDADES DE MONZONN Y PERNIA

A

B

C

Villasarracino

79.790

86.860

95.200

Villaherreros

29.290

30.300

35.095

Osornillo

18.180

25.250

22.015

San Llorente de la Vega

10.100

8.080

11.900

Fuente-Andrino

11.110

13.130

15.460

Naveros

9.090

14.645

12.495

Olmos de Río Pisuerga

7.070

10.605

10.710

Bárcena

17.170

20.200

23.205

Colmenares

11.110

9.090

11.900

Dehesa de Montejo

15.150

13.130

14.875

Calzada

16.665

26.765

28.560

Quintanilla de la Cueza

15.655

9.090

14.280

Bustillo de Potroviejo

27.775

27.775

32.130

Villacuende

8.080

9.595

11.900

Villamoronta

37.875

38.380

35.700

Villasavariego

27.270

25.250

28.560

Robladillo

22.220

23.230

19.635

Villamorco

25.250

23.230

20.825

Gozón

12.120

14.140

17.850

Bahillo

44.945

44.440

42.840

Calzadilla de la Cueza

12.120

12.120

17.850

Ravinos

10.100 


\begin{tabular}{|c|c|c|c|}
\hline MERINDAD DE SALDAÑA & A & B & $c$ \\
\hline Congosto .. & 6.565 & 5.555 & 9.520 \\
\hline Villovela & 18.685 & 19.190 & 20.850 \\
\hline Polvorosa $\ldots \ldots \ldots \ldots \ldots \ldots \ldots$ & 8.080 & 7.070 & 8.925 \\
\hline Renedo ....... & 10.100 & 7.070 & 4.760 \\
\hline Tabanera ........... & 12.120 & 10.605 & 13.685 \\
\hline Ayuela $\ldots . . . \ldots \ldots$ & 10.100 & 10.605 & 11.900 \\
\hline Villabasta . & 6.060 & 6.060 & 7.140 \\
\hline Villaproviano $\ldots . .$. & 10.100 & 7.070 & 13.090 \\
\hline Portillejo ........ & 5.555 & 5.555 & 5.355 \\
\hline Aldea $\ldots \ldots \ldots \ldots \ldots \ldots \ldots \ldots$ & 4.040 & 4.040 & 3.570 \\
\hline La Serna & 12.120 & 9.090 & 10.710 \\
\hline Villasur $\ldots \ldots \ldots \ldots \ldots \ldots \ldots \ldots$ & 6.060 & 4.040 & 4.760 \\
\hline Poza . & 12.625 & 20.200 & 22.610 \\
\hline Moslares ......... & 2.525 & 2.525 & 3.570 \\
\hline Retuerta. & 3.030 & 2.525 & 1.785 \\
\hline Villanuño & 6.060 & 6.525 & 7.140 \\
\hline Renedo del Monte $\ldots \ldots \ldots \ldots \ldots$ & 4.040 & 4.545 & 11.305 \\
\hline La Puebla & 13.635 & 19.190 & 19.635 \\
\hline
\end{tabular}


Fiscalidad y población pechera en tierra de Behetrias...

\begin{tabular}{|c|c|c|c|}
\hline MERINDAD DE CERRATO & A & $\mathrm{B}$ & c \\
\hline Torquemada .................. & 140.400 & 143.420 & 157.080 \\
\hline Villamediana $\ldots \ldots \ldots \ldots \ldots \ldots$ & 60.600 & 68.680 & 80.920 \\
\hline Peral & 12.120 & 9.090 & 10.710 \\
\hline Vaideolmillos $\ldots \ldots \ldots \ldots \ldots \ldots$ & 4.040 & 5.050 & 9.520 \\
\hline Alba de Cerrato $\ldots \ldots \ldots \ldots \ldots \ldots$ & 13.130 & 16.160 & 16.660 \\
\hline Esguevillas ........ & 32.320 & 30.300 & 29.750 \\
\hline Bertavillo $\ldots . .$. & 34.340 & 33.330 & 40.460 \\
\hline Castrillo de Onielo ... & 26.260 & 25.250 & 29.750 \\
\hline Antigüedad ... & 17.170 & 14.140 & 20.230 \\
\hline Royuela ...... & 23.230 & 24.240 & 28.560 \\
\hline Torrepadre .. & 5.55 & 7.070 & 9.520 \\
\hline Villaverde de Mojina...$\ldots \ldots \ldots \ldots$ & 2.525 & 3.030 & 8.330 \\
\hline Villahoz & 27.370 & 36.360 & 39.270 \\
\hline MERINDAD DE CAMPOS & A & B & c \\
\hline Becerril & 122.210 & 122.210 & 154.700 \\
\hline Frechilla & 173.720 & 171.700 & 192.780 \\
\hline Fuentes de D. Bermudo. & 85.850 & 91.910 & 110.670 \\
\hline Villarramiel & 46.460 & 49.490 & 71.400 \\
\hline Capillas & 40.400 & 44.440 & 51.170 \\
\hline Palacios de Campos & 38.280 & 38.380 & 45.220 \\
\hline Baquerín & 36.330 & 38.380 & 42.840 \\
\hline Autilla del Pino $\ldots \ldots \ldots \ldots \ldots \ldots$ & 51.510 & 49.490 & 60.690 \\
\hline
\end{tabular}


Boadilla de Rioseco 101.000

96.960

103.530

Cisneros

121.200

111.100

151.130

Cervatos de la Cueza

87.365

78.780

83.300

Mazuecos

31.815

30.300

35.700

Pozo de Urama

27.775

32.320

32.130

San Román de la Cuba

32.825

39.390

42.245

Villaicón

32.825

34.340

32.130

Arroyo

8.080

8.585

11.900

Población de Arroyo

25.250

25.250

27.370

Añoza

15.150

18.685

17.850

Abastillas

8.080

10.605

11.900

Abastas

15.150

19.190

23.800

Villanueva del Rebollar

14.645

17.170

19.040

Riberos de la Cueza

11.110

14.875 
Fiscalidad y población pechera en tierra de Behetrias...

\begin{tabular}{|c|c|c|c|}
\hline Buniel $\ldots \ldots \ldots \ldots$ & 20.200 & 24.240 & 29.750 \\
\hline Tobes y Raedo ............ & 6.060 & 7.070 & 9.520 \\
\hline Villayerno-Morquillas & 7.070 & 7.070 & 9.520 \\
\hline Celadilla-Sotobrín & 14.140 & 16.160 & 17.850 \\
\hline Quintanaortuño & 3.535 & 4.040 & 4.760 \\
\hline Melgosa & 2.020 & 2.020 & 3.570 \\
\hline Temiño ........... & 1.515 & 2.020 & 357 \\
\hline Albillos & 5.555 & 10.100 & 13.090 \\
\hline Rioseras & 30.300 & 29.290 & 22.610 \\
\hline Ubierna y San Marin ............. & 9.090 & 8.080 & 10.710 \\
\hline Hurones & 9.090 & 6.060 & 7.140 \\
\hline Celada de la Torre & 8.080 & 6.060 & 5.950 \\
\hline Sotragero & 10.605 & 11.110 & 1.390 \\
\hline Castil de Cerracín & 5.555 & 6.060 & 7.140 \\
\hline Mata Sobresierra ......... & 1.010 & 2.020 & 1.190 \\
\hline Maruellar ............... & 10.100 & - & - \\
\hline Villanueva de Río-Ubierna & 24.240 & 23.230 & - \\
\hline Modubar de la Emparedada & 6.060 & 7.070 & - \\
\hline Cojobar & 6.060 & 4.040 & - \\
\hline Modubar de la Cuesta & 11.100 & 7.070 & - \\
\hline Umienta (?) & 6.565 & 4.040 & - \\
\hline Quintanilla Morocisla & 2.020 & 2.020 & - \\
\hline Olmosalbos & 1.515 & 2.020 & - \\
\hline Robledo Cavetemino (?) & 7.070 & 9.090 & - \\
\hline Gradilla de la Polera & 8.080 & 7.070 & - \\
\hline Riocerezo $\ldots \ldots \ldots \ldots \ldots \ldots$ & 25.250 & 28.280 & - \\
\hline Nidáguila & 5.555 & 7.070 & 一 \\
\hline Quintana de las Torres $\ldots . . \ldots \ldots$. & 19.690 & 20.200 & - \\
\hline Marmellar & - & 21.210 & - \\
\hline
\end{tabular}


C

\begin{tabular}{|c|c|c|c|}
\hline Villafuentes $\ldots \ldots \ldots \ldots \ldots \ldots \ldots$ & 1.010 & 1.010 & 1.190 \\
\hline Villar Gómez & 10.100 & 10.100 & 13.090 \\
\hline Cogollos . & 15.150 & 17.170 & 21.420 \\
\hline Valdorros ........ & 10.100 & 10.100 & 11.900 \\
\hline Montuenga & 3.030 & 3.030 & 7.140 \\
\hline Villamayor de Montes $\ldots . \ldots \ldots \ldots$ & 32.320 & 30.300 & 40.460 \\
\hline Cael $\ldots \ldots \ldots \ldots \ldots \ldots \ldots \ldots \ldots$ & 23.230 & 18.180 & 16.660 \\
\hline Arenillas de Candemuño & 2.020 & 3.030 & 4.760 \\
\hline Mazuelo & 10.100 & 9.090 & 11.900 \\
\hline Cayuela & 5.050 & 2.020 & 4.760 \\
\hline Villamiel & 4.040 & 4.040 & 9.520 \\
\hline Cabia & 17.170 & 20.200 & 24.990 \\
\hline Quintanillas, Las & 19.190 & 30.300 & 40.460 \\
\hline Villagutierre $\ldots$ & 5.050 & 5.050 & 8.330 \\
\hline Vilviestre $\ldots \ldots$. & 14.140 & 15.150 & 21.420 \\
\hline Iglesias . & 45.450 & 44.440 & 57.120 \\
\hline Tamarón & 14.640 & 14.645 & 20.230 \\
\hline Celada del Camino & 15.650 & 17.675 & 20.230 \\
\hline Villaldemiro & 10.100 & 12.120 & 15.470 \\
\hline Villanueva de las Carretas & 3.030 & 3.030 & 3.570 \\
\hline Presencio & 55.045 & 50.500 & 46.410 \\
\hline Mahamud & 40.400 & 40.400 & 35.700 \\
\hline Santa Maria del Campo & 36.865 & 36.360 & 33.320 \\
\hline
\end{tabular}


Fiscalidad y población pechera en tierra de Behetrias...

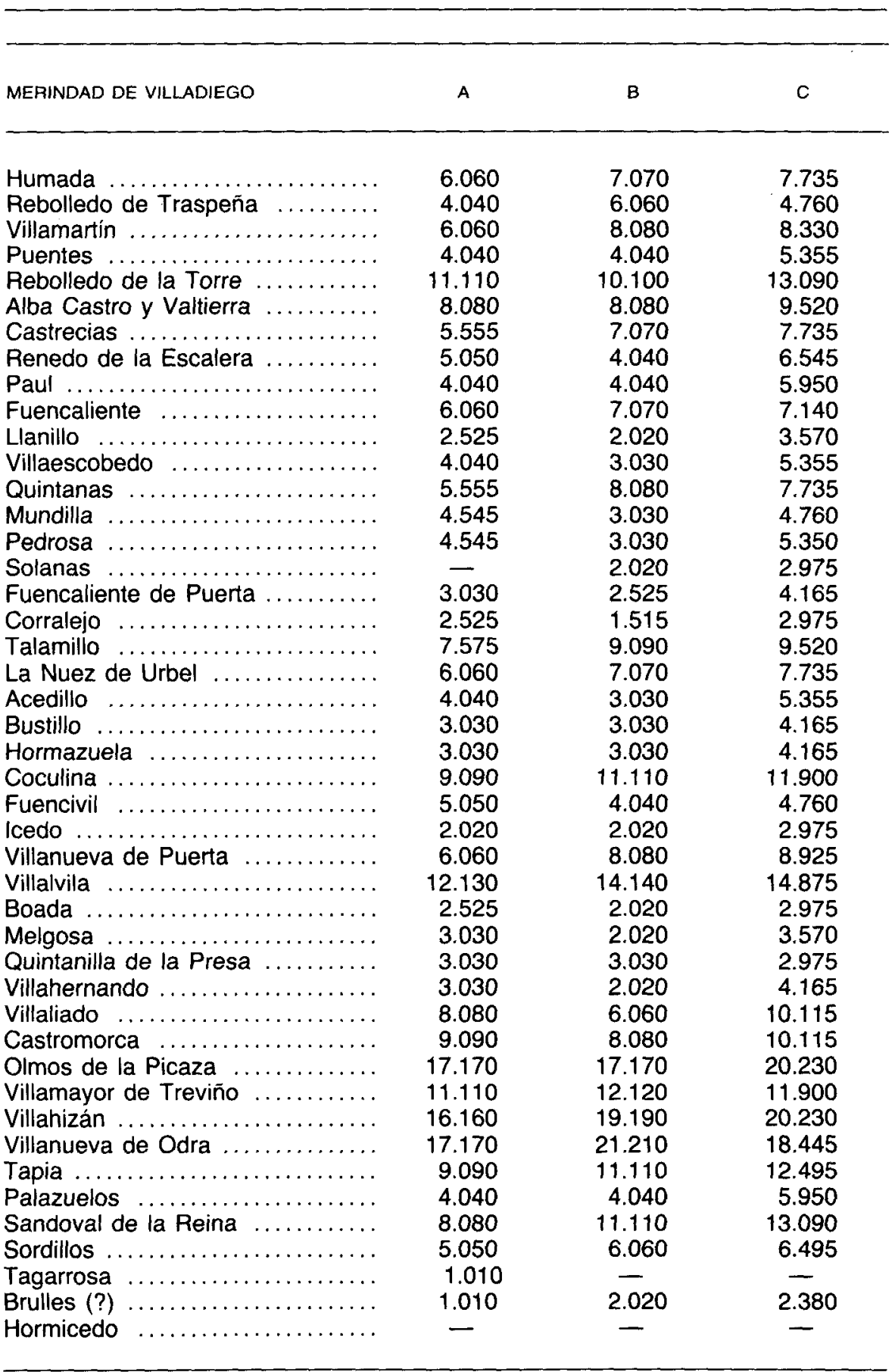




\begin{tabular}{|c|c|c|c|}
\hline Palazuelos & 4.040 & 5.050 & 5.950 \\
\hline Judego y Villandiego $\ldots . . . . . . .$. & 36.660 & 36.360 & 42.840 \\
\hline Balbases, Los & 46.460 & 46.460 & 54.740 \\
\hline Revilla-Vallegera & 31.310 & 31.310 & 36.890 \\
\hline Villalco $\ldots . . . .$. & 10.100 & 10.100 & 17.850 \\
\hline Cordovilla & 10.100 & 12.120 & 7.140 \\
\hline Valbuena de Río Pisuerga & 2.545 & 2.020 & 4.760 \\
\hline Itero de la Vega ..... & 30.300 & 34.340 & 40.460 \\
\hline Arenillas de Río Pisuerga & 42.420 & 45.450 & 53.350 \\
\hline Melgar de Fernamental. & 127.260 & 127.260 & 126.140 \\
\hline Valtierra de Río Pisuerga. & 8.080 & 8.080 & 7.140 \\
\hline Padilla de Arriba ... & 33.330 & 30.300 & 35.700 \\
\hline Padilla de Abajo $\ldots . \ldots \ldots \ldots \ldots$ & 45.450 & 48.480 & 57.120 \\
\hline Grijalba ..... & 22.220 & 22.220 & 26.180 \\
\hline Villegas y Villamorón & 28.280 & 30.300 & 35.700 \\
\hline Sasamón $\ldots \ldots \ldots \ldots$ & 76.760 & 78.780 & 85.680 \\
\hline Castrillo de Murcia & 40.400 & 42.420 & 49.980 \\
\hline Villasandino & 78.780 & 78.780 & 92.820 \\
\hline Santoyo & 54.540 & 56.560 & 89.250 \\
\hline Boadilla del Camino $\ldots \ldots \ldots \ldots \ldots$ & 38.380 & 38.380 & 45.220 \\
\hline Melgar de Yuso & 10.100 & 8.080 & 9.520 \\
\hline Villasilos & 43.330 & 45.450 & 53.350 \\
\hline Lantadilla & 67.160 & 66.660 & 78.540 \\
\hline Villodre & 10.100 & 8.080 & 16.660 \\
\hline Pedrosa de Socastro. & 23.230 & 26.260 & 30.940 \\
\hline Villamedianilla & 6.060 & 6.060 & 8.330 \\
\hline Vallunquera & 2.020 & 1.010 & 2.380 \\
\hline Hinestrosa & 9.090 & 8.080 & 9.520 \\
\hline Perex & - & - & 一 \\
\hline Puente Itero & - & - & - \\
\hline
\end{tabular}


Fiscalidad y población pechera en tierra de Behetrias...

MERINDAD DE CASTRO (POR TREVIÑO)

A

B

C

Hormazas, Las

30.805

34.340

40.460

Pedrosa de Río-Urbel

29.290

32.320

30.940

Cañizar de los Ajos

24.240

24.240

29.750

Santibáñez de Zarzaguda

42.420

40.400

45.220

Lodoso

14.140

15.150

15.470

Pedrosa del Páramo

12.120

12.120

14.280

Susinos

13.130

14.140

16.660

Manciles

10.100

10.100

13.090

Quintanilla de Pedro de Abarca ..

4.040

5.050

4.760

San Pantaleón

3.030

4.040

3.570

Huermeces

5.050

7.070

8.330

Ruyales del Páramo

3.030

1.010

Tremellos, Los

10.100

10.100

15.470

Cítores del Páramo

6.060

9.090

9.520

Roscón Monasteruelo

11.110

12.120

15.470

Palacios de Benaver

20.200

22.220

24.990

Villorejo

20.200

20.200

24.990

Abellanosa del Páramo

14.040

16.160

21.420

Miñón

8.080

9.090

9.0520

Rebolledas, Las

9.090

6.060

8.330

Zumel

9.090

8.080

10.710

Santa Maria de Tajadura

9.090

8.080

9.520

San Pedro Samuel

14.140

12.120

16.660

Celadas, Las

12.120

8.080

9.520 
B

29.290

34.510

Tripiana

33.340

30.300

35.700

Cerratón de Rioja

29.290

15.150

19.190

Manjarres

Villar de Torre

20.230
MERINDAD DE SANTO DOMINGO DE SILOS

Tordomar

Paules del Agua

Pinilla de Trasmonte

Quintana Raya

Iglesiarrubia

Arauzo de Salce

Arauzo de Torre

Arauzo de Miel

Quintanilla del Agua

Castrillo de Solarana

Nebreda

Cebrecos

Zacuar (?)

Hinojar del Rey

Hontoria de Valdearados

Cilleruelo de Arriba

Valdeande

Quintanilla del Coco

Pineda de Trasmonte

Baños
A

B

14.645

4.040

30.300

17.170

5.050

12.120

8.080

33.330

18.180

17.170

16.665

13.130

28.280

10.100

18.180

8.080

13.130

8.080

16.160

15.150
C 
Fiscalidad y población pechera en tierra de Behetrias...

B

C

\begin{tabular}{|c|c|c|c|}
\hline Santa Maria de Ribarredonda .... & 28.280 & 24.240 & 28.560 \\
\hline Buero de Sierra & 2.020 & 2.020 & 2.380 \\
\hline Lermilla .... & 3.030 & 4.040 & 3.570 \\
\hline Movilla & 1.010 & 1.010 & 1.190 \\
\hline Aguilar de Bureba & 14.140 & 12.120 & 14.280 \\
\hline Quintana-Urria ........ & 6.060 & 4.040 & 4.760 \\
\hline Terrazos .. & 3.030 & 9.090 & 8.330 \\
\hline Rojas & 5.050 & 8.080 & 9.520 \\
\hline Castil de Lences ... & 2.020 & - & - \\
\hline Barrios de Bureba. & 4.040 & 6.060 & 7.140 \\
\hline Parte, La ........... & 1.100 & - & 一 \\
\hline Quintana Suso ....... & 2.020 & 1.010 & 2.380 \\
\hline Quitana de Bureba .. & 5.050 & 3.030 & 5.950 \\
\hline Salas de Bureba & 6.060 & 4.040 & 5.355 \\
\hline Zuñeda .... & 22.220 & 22.220 & 21.420 \\
\hline Calzada ....... & 6.060 & 2.020 & 2.380 \\
\hline Cubo & 21.230 & 14.140 & 17.850 \\
\hline Cameno ... & 20.200 & 16.160 & 17.850 \\
\hline Carcedo & 5.050 & 3.030 & 5.355 \\
\hline Rublacedo de Arriba .. & 3.030 & 3.030 & 4.760 \\
\hline Rublacedo de Abajo $. . . \ldots \ldots \ldots . .$. & 8.080 & 8.080 & 5.950 \\
\hline Quintanilla de Bon .. & 4.040 & 8.080 & 9.520 \\
\hline Santaolalla & 1.100 & - & 1.190 \\
\hline Valdearnedo $\ldots . . . . . . . . . . . . .$. & 2.020 & 3.030 & 1.190 \\
\hline Miraveche & 25.250 & 24.240 & 27.370 \\
\hline Fieinoso & 9.090 & 4.040 & 9.520 \\
\hline Salinillas & 3.030 & 6.060 & 4.760 \\
\hline Hermosilla ................... & 4.040 & 1.010 & 1.190 \\
\hline
\end{tabular}

